\title{
A reliable rubric for evaluating medical apps
}

FAST

TRACK

It is critical to assess authority or authorship to determine that the app developers are reputable, qualified, and authoritative enough to create the medical content in question

\section{$A C O G$}

Developed in collaboration with the American College of Obstetricians and Gynecologists
$\mathrm{T}$ o help ObGyns evaluate mobile apps for use in clinical practice, the American College of Obstetricians and Gynecologists Presidential Task Force of Dr. Eva Chalas recommends a quantitative rubric that was developed by the American Society of Health-System Pharmacists (ASHP) for evaluating drug information apps (TABLE). ${ }^{1}$ Criteria are graded on a point scale of 1 to 4 , with 1 point indicating major deficiencies and 4 points indicating no deficiencies.

The ASHP used the following criteria in evaluating mobile apps:

- Usefulness: the app's overall usefulness in a particular practice setting

- Accuracy: overall accuracy of the app should be thoroughly examined

- Authority: it is critical to assess authority or authorship to determine that the developers are reputable, qualified, and authoritative enough to create the medical content in question

- Objectivity: to determine if content is fair, balanced, and unbiased

- Timeliness: given that medical information is continually changing, an app must be evaluated based on the timeliness of its content

- Functionality: how the app downloads, deploys, and operates across devices and software platforms (that is, iOS, Android)

- Design: well-designed apps are generally more user friendly and, therefore, useful. They should require minimal or no training and have easily discernible buttons, a clean and uncluttered format, consistent graphics layout, terminology appropriate for the intended audience, streamlined navigation

The authors report no financial relationships relevant to this article.

doi: 10.12788/obgm.0094

\section{ACOG Presidential TASK Force MEMBERS}

Nicholas Kulbida, MD, is Chair, Department of Obstetrics and Gynecology, Ellis Medicine, and Medical Director, Bellevue Woman's Care Center, Schenectady, New York, and OB Hospitalist Group, Greenville, South Carolina. Donna Montalto, MPP, is Chief of Staff and SVP, Marketing and Communications, Optum Tri-State, Westchester, New York.

Hartaj K. Powell, MD, MPH, is OB Hospitalist, Ascension Saint Agnes Hospital, Baltimore, Maryland.

Krista Wagoner, MD, is Assistant Professor of Obstetrics and Gynecology, Director, Clerkship in Obstetrics and Gynecology, MUSC East Cooper Women's Center, Medical University of South Carolina, Charleston.

Richard Waldman, MD, is Chair,

Department of Ob/Gyn, St. Joseph's Hospital, and Partner, Associates for Women's Health, Syracuse, New York.

Matthew Wells, MD, MBA, is Attending Physician, Women and Children's Services, NYU Langone Health Hospital, and Unified Women's Healthcare, Mineola, New York.

without extraneous steps/gestures, appropriate-sized text, and sufficient white space to improve readability.

- Security: Many apps collect a wide array of personal and device data. Collected data has the potential for being sold to third parties for marketing and advertising purposes. Apps should disclose their privacy policy and provide an explanation as to why personal data are being collected. If personal identifiable information (PII) is collected, then the app should be encrypted. If protected health information (PHI) is collected, the app must follow 


\section{TABLE ASHP rubric for evaluating mobile drug information apps}

\begin{tabular}{|c|c|c|c|c|}
\hline \multirow{2}{*}{$\begin{array}{l}\text { Criteria } \\
\text { Usefulness } \\
\text { Points: __/4 }\end{array}$} & \multicolumn{4}{|c|}{4 points $=$ no deficiencies, 1 point $=$ major deficiencies } \\
\hline & $\begin{array}{l}\text { App is relevant and would } \\
\text { be very useful in daily } \\
\text { practice; will improve } \\
\text { efficiency or knowledge } \\
\text { base }\end{array}$ & $\begin{array}{l}\text { App is somewhat relevant } \\
\text { and could be useful in } \\
\text { practice; may improve } \\
\text { efficiency or knowledge } \\
\text { base }\end{array}$ & $\begin{array}{l}\text { App is not very relevant and } \\
\text { probably won't be useful in } \\
\text { daily practice; may or may } \\
\text { not improve efficiency or } \\
\text { knowledge }\end{array}$ & $\begin{array}{l}\text { App is irrelevant and } \\
\text { would not be useful in } \\
\text { daily practice; may hurt } \\
\text { efficiency or knowledge } \\
\text { base }\end{array}$ \\
\hline Points: ___ 4 & $\begin{array}{l}\text { Source material is } \\
\text { appropriate and cited } \\
\text { throughout; clinical } \\
\text { content is thorough/ } \\
\text { comprehensive }\end{array}$ & $\begin{array}{l}\text { Most source material is } \\
\text { appropriate and cited; } \\
\text { clinical content relatively } \\
\text { thorough }\end{array}$ & $\begin{array}{l}\text { Some material is } \\
\text { inappropriate or has few } \\
\text { citations; app lacks some } \\
\text { important clinical data }\end{array}$ & $\begin{array}{l}\text { No references to source } \\
\text { material; missing } \\
\text { important content; } \\
\text { deficiencies may cause } \\
\text { patient harm }\end{array}$ \\
\hline Points: $\quad / 4$ & $\begin{array}{l}\text { Publisher and/or authors } \\
\text { clearly listed; app } \\
\text { developers are considered } \\
\text { to be content experts }\end{array}$ & $\begin{array}{l}\text { Publisher and/or authors } \\
\text { are listed; developers } \\
\text { seem trustworthy and } \\
\text { qualified }\end{array}$ & $\begin{array}{l}\text { Publisher and/or authors } \\
\text { difficult to locate; app } \\
\text { developers may or may } \\
\text { not be qualified }\end{array}$ & $\begin{array}{l}\text { Publisher and/or authors } \\
\text { not listed; app developers } \\
\text { are not qualified/reputable }\end{array}$ \\
\hline Objectivity & $\begin{array}{l}\text { Content is fair and } \\
\text { balanced; no bias evident; } \\
\text { app is only for clinical } \\
\text { purposes }\end{array}$ & $\begin{array}{l}\text { Content is relatively fair } \\
\text { and balanced; no overt } \\
\text { promotion of products is } \\
\text { noticed }\end{array}$ & $\begin{array}{l}\text { Content may be biased; } \\
\text { some product promotion } \\
\text { is evident }\end{array}$ & $\begin{array}{l}\text { Content is heavily biased; } \\
\text { app is only for promotional } \\
\text { purposes }\end{array}$ \\
\hline Points: __ $/ 4$ & $\begin{array}{l}\text { Clinical content is current } \\
\text { and will be updated } \\
\text { regularly }\end{array}$ & $\begin{array}{l}\text { Clinical content is } \\
\text { relatively current; may lack } \\
\text { some new data but will } \\
\text { likely be updated }\end{array}$ & $\begin{array}{l}\text { Content is somewhat old, } \\
\text { but still useful to clinical } \\
\text { practice; future updates } \\
\text { unclear }\end{array}$ & $\begin{array}{l}\text { Clinical content is out } \\
\text { of date and irrelevant or } \\
\text { harmful to practice; will not } \\
\text { be updated in the future }\end{array}$ \\
\hline Functionality & $\begin{array}{l}\text { Installs and functions } \\
\text { perfectly; no technical } \\
\text { problems are evident or } \\
\text { anticipated }\end{array}$ & $\begin{array}{l}\text { Rarely crashes, freezes, } \\
\text { or has other technical } \\
\text { problems }\end{array}$ & $\begin{array}{l}\text { Occasionally crashes, } \\
\text { freezes, or has other } \\
\text { technical problems }\end{array}$ & $\begin{array}{l}\text { Repeatedly crashes, } \\
\text { freezes, or has other } \\
\text { technical problems; } \\
\text { contains malware }\end{array}$ \\
\hline Points: ___ $/ 4$ & $\begin{array}{l}\text { Incredibly easy to use } \\
\text { and navigate; all design } \\
\text { elements are consistent } \\
\text { and easy to understand }\end{array}$ & $\begin{array}{l}\text { Relatively easy to use and } \\
\text { navigate; most design } \\
\text { elements are consistent } \\
\text { and easy to understand }\end{array}$ & $\begin{array}{l}\text { Often difficult to use and } \\
\text { navigate; design elements } \\
\text { may hurt some of the } \\
\text { app's usability }\end{array}$ & $\begin{array}{l}\text { Very difficult to use and } \\
\text { navigate; design elements } \\
\text { definitely hinder usability }\end{array}$ \\
\hline Points: __ $/ 4$ & $\begin{array}{l}\text { Free of malicious software; } \\
\text { privacy statement } \\
\text { available; personal data } \\
\text { are encrypted/protected }\end{array}$ & $\begin{array}{l}\text { Free of malicious software; } \\
\text { privacy statement might } \\
\text { be available; personal data } \\
\text { are probably protected }\end{array}$ & $\begin{array}{l}\text { May contain malicious } \\
\text { software; privacy } \\
\text { statement difficult to find; } \\
\text { unclear if personal data } \\
\text { are protected }\end{array}$ & $\begin{array}{l}\text { Contains malicious } \\
\text { software; privacy } \\
\text { statement unavailable; } \\
\text { personal data are not } \\
\text { protected }\end{array}$ \\
\hline Points: ___ & $\begin{array}{l}\text { Price of app is } \\
\text { appropriate, given its } \\
\text { content and features }\end{array}$ & $\begin{array}{l}\text { Price of app is reasonable, } \\
\text { considering its content } \\
\text { and features }\end{array}$ & $\begin{array}{l}\text { Price of app is a barrier } \\
\text { and may not be worth the } \\
\text { content provided }\end{array}$ & $\begin{array}{l}\text { App is overpriced and not } \\
\text { worth the cost }\end{array}$ \\
\hline $\begin{aligned} \text { Totals: } \\
\\
\quad 136\end{aligned}$ & Comments & & & \\
\hline
\end{tabular}

Abbreviation: ASHP, American Society of Health-System Pharmacists.

Used with permission.

compliance with HIPAA/HITECH

(Health Insurance Portability and Accountability Act/Health Information Technology for Economic and Clinical Health Act). Addition- ally, apps should not compromise the security or functionality of the mobile device being used.

- Value: appropriateness of an app's cost.

\section{Reference}

1. Hanrahan C, Aungst TD, Cole S. Evaluating mobile medical applications. American Society of HealthSystem Pharmacists eReports. https://www.ashp .org/-/media/store-files/mobile-medical-apps. ashx. Accessed January 22, 2021. 


\section{ACOG PRESIDENTIAL TASK FORCE SERIES ON PREVENTIVE HEALTH CARE Focus on cancer risk}

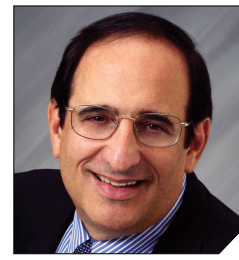

Richard Waldman, MD

Dr. Waldman is Past President of the American College of Obstetricians and Gynecologists, Past President of Associates for Women's Medicine, and Immediate Past Chairman, Department of Obstetrics and Gynecology, St. Joseph's Hospital, Syracuse, New York.

\section{ACOG}

Developed in collaboration with the American College of Obstetricians and Gynecologists ereditary cancer risk assessment is the key to identifying patients and families who are at increased risk for developing cancer. The knowledge generated by cancer risk assessment impacts clinical decisions that obstetricians and gynecologists and their patients make every day. Previvors-patients predisposed to developing cancer, because of their family history or a pathogenic gene variant, who have not had cancer-benefit from counseling, heightened surveillance, and medical and surgical options.

For the last 25 years, this field has been growing dramatically, and although the scientific advances are present, only $15.3 \%$ of patients with a personal history of breast or ovarian cancer who meet hereditary cancer testing criteria have been tested. ${ }^{1}$ As many as 1 in 4 women who present for a gynecologic examination may have a personal history or a family history that qualifies them for genetic testing. ${ }^{2}$

\section{Cancer risk app considerations}

The ability to leverage mobile device applications can provide clinicians and patients with

The author reports no financial relationships relevant to this article.

doi: 10.12788/obgm.0111 a useful screening tool to identify women who are at increased cancer risk. Only a handful of apps are available today and most are geared to patients. Such apps explore the different testing modalities, including genetic testing, as well as treatment options. When evaluating the best app for patients, using the ACOGrecommended rubric shown on page 35 , the qualities to keep in mind and that should score 4 out of 4 include design, authority, usefulness, and accuracy.

A few apps provide reminders for appointments, such as mammograms, magnetic resonance imaging, or breast selfexams, and allow patients to track treatment plans. To date, no app addresses prevention and treatment opportunities that are specific to patients who have a hereditary predisposition. At least one app lists hereditary cancer testing guidelines. Many more apps are geared toward individuals with cancer rather than toward previvors.

As ObGyns, we have an opportunity to educate and identify women and, subsequently, better counsel women identified as at increased risk for developing cancer. We can utilize medical apps to efficiently incorporate this screening into clinical practice. 


\title{
Mobile apps in ObGyn practice: Tools for enhancing women's preventive health care
}

\author{
Mobile apps are putting evidence-based medicine, society guidance, and \\ health recommendations at your-and your patients'-fingertips. An ACOG \\ Presidential Task Force describes their goals in recommending an ASHP- \\ developed rubric to evaluate medical apps and how apps can fit into the \\ preventive health care discussion at the annual visit.
}

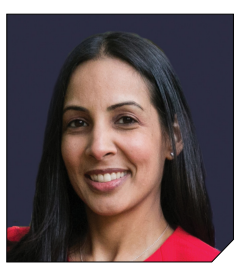

Hartaj K. Powell, MD, MPH

Dr. Powell is OB Hospitalist, Ascension Saint Agnes Hospital, Baltimore, Maryland.

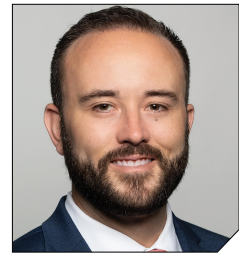

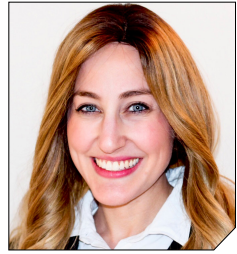

Eva Hoffmann, MD Dr. Hoffmann is Resident Physician, Department of Obstetrics and Gynecology, NYU Langone Hospital-Long Island, Long Island School of Medicine, Mineola, New York.
$\mathrm{D}$ r. Eva Chalas' American College of Obstetricians and Gynecologists (ACOG) Presidential Initiative "Revisit the Visit" was established with a vision of what the future holds for obstetrician-gynecologists. As ObGyns, we are often the first physician to care for the patient in her adulthood, and we continue to do so across the entirety of her life. This gives us the opportunity to form longterm partnerships with women to address important preventive health care measures. The annual visit can serve as a particularly impactful point of care to achieve specific preventive care objectives and offer mitigation strategies based on patient-specific risk factors. With an eye to the future, we have a great opportunity to continue to reinvent ourselves and highlight the positive impact we can make on women's long-term health.

The authors report no financial relationships relevant to this article.

doi: 10.12788/obgm.0112

\section{Evolutionary changes in ObGyn}

Preventive medicine guidelines have evolved to reflect enhanced cervical cancer screening tests, longer-acting contraceptive options, and better data on the lack of utility of the annual pelvic exam that has changed the focus of the annual visit for both physicians and patients. ${ }^{1}$ These changes allow us to pivot and leverage the trust we build with our patients to make meaningful impacts in preventing chronic disease, improving prepregnancy health, reducing maternal mortality and morbidity, and improving the quality and longevity of our patients' lives. New guidelines, coupled with the knowledge of the leading causes of morbidity for women, provide the chance to incorporate areas of screening and intervention that, while we are capable of addressing, we traditionally have not done so for various reasons.

The ACOG Presidential Task Force identified 5 areas of preventive health that significantly influence the long-term morbidity of women: obesity, cardiovascular disease, 
preconception counseling, diabetes, and cancer risk. ObGyns are uniquely positioned to identify and initiate the conversation and subsequently manage, treat, and address these critical health areas. To make this daunting task more manageable, the Task Force not only published webinars to address the clinical knowledge pertaining to these areas of health but also specifically looked at how to use technology to aid obstetrician-gynecologists in addressing them with patients.

\section{Making use of technology in clinical practice}

Technology is emerging as an influential player in health care. Major corporations, such as Amazon, Google, Apple, and Facebook, are making headlines in health care as they consider strategies (moves) to revolutionize technology and, in turn, patient visits like we have never seen before. Examples include incorporating artificial intelligence in a patient's care and allowing better access for primary care.

The changes that we will see over the next

As medical experts, it is incumbent on us to pay careful attention to the accuracy, authority, objectivity, timeliness, and security of any app we consider incorporating into clinical practice

\section{The recommended rubric for evaluating apps}

To evaluate mobile drug information apps, the Task Force members recommend a userfriendly, convenient rubric developed by the American Society of Health-System Pharmacists (ASHP) (see page 35). The rubric can help obstetrician-gynecologists evaluate and compare the value of various medical apps that specifically address obesity, diabetes mellitus, cardiovascular disease, improving maternal morbidity with enhanced preconception counseling, and cancer risk assessment.

The authors of this Task Force series have attempted to highlight the key features of an app as it pertains to a particular area of focus. It is important to keep in mind the primary user and the goal when choosing or recommending an app for practice or for patient use. The ASHP's rubric is a tool meant to aid clinicians in evaluating medical apps, but it is ultimately the user's decision to determine if the deficiencies of an app should deter its use. Although all the criteria are relevant and important, as medical experts it is incumbent on us to pay careful attention to the accuracy, authority, objectivity, timeliness, and security of any app we consider incorporating into clinical practice.

While integrating the use of medical apps into clinical practice will be novel for some, for others, junior Fellows in particular, it has become part of their practice and education. Dr. Eva Hoffmann, Chief Resident in the NYU Langone Health System, offers this perspective: "As medical trainees we use mobile apps to enhance our patient interaction and guide high-quality, continuous care. In today's modern technological world, apps help keep us up to date with the ever-changing guidelines in pregnancy and routine gynecologic care as well as communicate directly and discreetly with a patient whenever the need arises. The most significant apps provide guidance on abnormal Pap results, indicated deliveries prior to 39 weeks, and the ability to respond to obstetrical emergencies. They also allow for quick society-endorsed references in seconds. Apps have changed the way 
that we practice by providing evidence-based medicine literally at our fingertips-in a shareable and communicable way-making the practice of medicine even more efficient and effective."

\section{Opportunity to reaffirm expertise}

Dr. Chalas' initiative was meant to shed light on the opportunity obstetrician-gynecologists have to reassert themselves as women's health experts, to consider redefining their practice by incorporating new preventive guidelines, and to leverage medical apps for achieving better health outcomes for women across their lifetime. We hope that by opening a dialogue about how ubiquitous medical apps are (for both physicians and patients) in today's health arena, how many apps are inaccurate and/or misused, and how a simple rubric can be used to assess an app's value, you are inspired and feel more comfortable to incorporate medical apps into your practice.

Health care will continually undergo advancements, and as a specialty we must evolve to address women's needs. Obstetrician-gynecologists are well suited to contribute significantly to the well-being of women and mothers. We can leverage technology- based apps to help us redefine our roles and priorities at the patient's annual visit. We can reaffirm ourselves as the leading women's health care physicians.

\section{An additional resource}

To enhance your understanding of apps and how to evaluate them, Dr. Katherine Chen's App Review series in OBG MANageMENT is a great resource and building block for enhancing your toolbox for the annual visit. Dr. Chen's own research and APPLICATIONS scoring system is used to evaluate selected mobile apps. ${ }^{2}$ In addition, each article includes a table that details the apps' features based on a shortened version of the APPLICATIONS scoring system, APPLI (app comprehensiveness, price, platform, literature used, and important special features).

\section{In appreciation}

The members of this Task Force want to thank the Editorial Board and staff of OBG MANAGEMENT for their support and assistance in publishing this series. We especially want to thank Dr. Robert Barbieri for his support and appreciation for the role technology and medical mobile apps play in our daily practice.

\section{References}

1. Women's Preventive Services Initiative website. Recommendations for well-woman care: a well-woman chart. https:// www.womenspreventivehealth.org/wellwomanchart/. Accessed June 11, 2021.
2. Chyjek K, Farag S, Chen KT. Rating pregnancy wheel applications using the APPLICATIONS scoring system. Obstet Gynecol. 2015;125:1478-1483.
FAST

TRACK

Health care will continually undergo advancements, and as a specialty we must evolve to address women's needs 